\title{
Using the Ordered Probit Model to Predict Drivers for Adoption of Multiple Soil Fertility Management and Conservation Technologies in Potato Production Systems in Uganda
}

\author{
Robert Muzira ${ }^{*}$, John Steven Tenywa2 ${ }^{2}$, Twaha Ali Basamba ${ }^{2}$ \\ ${ }^{1}$ National Agricultural Research Organization, Mbarara City, Uganda \\ ${ }^{2}$ Makerere University, Kampala, Uganda \\ Email: ^nrmuzira@yahoo.com
}

How to cite this paper: Muzira, R., Tenywa, J.S. and Basamba, T.A. (2021) Using the Ordered Probit Model to Predict Drivers for Adoption of Multiple Soil Fertility Management and Conservation Technologies in Potato Production Systems in Uganda. Open Access Library Journal, 8: e7922.

https://doi.org/10.4236/oalib.1107922

Received: September 2, 2021

Accepted: December 12, 2021

Published: December 15, 2021

Copyright $\odot 2021$ by author(s) and Open Access Library Inc.

This work is licensed under the Creative Commons Attribution International License (CC BY 4.0).

http://creativecommons.org/licenses/by/4.0/

\begin{abstract}
Potato (Solanum tuberosum L.) is a major staple food crop and a source of household income in Eastern Africa, particularly the highland areas. Potato production systems are characterized by a spiral of nutrient depletion, leading to low tuber yields and quality. In order to increase potato production particularly in the highlands of south-western Uganda, farmers have destroyed soil conservation structures and encroached on marginal areas. This has further escalated land degradation in form of soil nutrient exhaustion and erosion on the hill-slopes. To reverse soil nutrient exhaustion, CIAT implemented a project named "Enabling Rural Innovation-ERI" in an alliance with other research and development partners. The main objective of ERI project was to enhance farmers' capacity to invest in sustainable soil fertility management and conservation in potato production systems through 1) farmers' training in soil fertility management and conservation; and 2) linking farmers to urban markets. After five years of farmers getting engaged in potato-agro enterprise, another study was conducted to assess influence of market linkage and other socio-economic factors on farmer's investments in multiples soil fertility management and conservation innovations in potato production systems. Using probit model, it was revealed that farmer's likelihood to invest in two or more soil fertility management and conservation innovations was influenced by his age, education level, hired labor, possession of small ruminants and enhanced market linkage.
\end{abstract}

\section{Subject Areas}

Agricultural Engineering 


\section{Keywords}

Potato, Soil fertility, Soil Conservation, Market Linkages, Farmers' Investments

\section{Introduction}

The Green Revolution that intensely increased grain yields of cereals both in Latin America and Asia indicates that rural livelihoods in the developing world have great potential of being transformed through increased use of multiple and improved agricultural technologies [1]. Influence of improved technologies to agricultural productivity and incomes in smallholder farming systems has been widely reported [1] [2] [3] [4]. Successful agricultural transformation experienced, the world over, has occurred due to intensive use of integrated and improved technologies like fertilizers, improved seed and soil and water conservation technologies [4] [5].

Over $75 \%$ of Uganda population estimated at 45 million is engaged in agriculture. Nonetheless, $41 \%$ of the population has been reported to be in abject poverty [6]. Increasing agricultural production and enhancing market access for farmers could be one of the avenues of improving rural household incomes and livelihoods. With support from developing partners, the government of Uganda has used different programs and projects in its efforts to improve agricultural production and rural livelihood. These programs and projects include Operation Wealth Creation (OWC) through National Agricultural Advisory Services (NAADS), Agricultural Technology and Agribusiness Advisory Services (ATAAS), Vegetable Oil Development (VOD), Community Agricultural Infrastructure Improvement (CAII) and District Livelihoods Support (DLS) among others. Improved technologies for soil fertility improvement and water conservation have also been developed and disseminated, particularly by the $\mathrm{Na}$ tional Agricultural Research Organization (NARO) in order to address challenges related to soil degradation in smallholder farming systems. To add to these efforts, International Center for Tropical Agriculture (CIAT) in collaboration with other research and development partners implemented an allied project code named "Enabling Rural Innovation-ERI" in the highlands of southwestern Uganda. Using Farmer Field School Approaches, potato farmers were trained in improved soil fertility management and conservation necessary for potato production. The farmers were later linked to urban markets, which enabled them to practice contract farming for five consecutive years. Through memorandum of understanding, farmers supplied 5.7 tons of potato to urban markets fortnightly. Hence, this study was designed to assess impact of linking farmers to markets in relation to other socioeconomic factors on levels of adoption of multiple technologies in the potato production systems in the highlands of southwestern Uganda. 


\section{Methodology}

\subsection{Study Area}

\subsubsection{Location and Physiographic}

This study was conducted in Kamuganguzi sub-County in Kabale district, in the highlands of south-western Uganda. Kabale district covers an area of approximately $1800 \mathrm{Km}^{2}$, and lies at an altitudes between 1200 and $2347 \mathrm{~m}$ above sea level [7]. The mean annual rainfall of the district is $1000 \mathrm{~mm}$; it is bimodal and precipitation is usually gentle and evenly distributed. Temperatures range between $9^{\circ} \mathrm{C}$ to $23^{\circ} \mathrm{C}$.

The highlands of south-western Uganda are made up of undulating hills, with slopes ranging from $23 \%$ to above $45 \%$, with numerous ridges and cones. The hill-slopes are characterized by high erosion potential and shallow dark brown soils of low productivity. The valley bottom soils are mainly deep humose brown loam, with moderate to high natural productivity [7]. Soil fertility decline is dramatic, and mostly a result of continuous cultivation, soil erosion and limited investments in soil fertility enhancement resources [8]. Most of the landscape (75\%) is highly fragmented and intensively cultivated, with few fields under fallow or applied with fertilizers [9].

\subsubsection{Criteria for Site Selection}

Kabale district was purposively selected for this study because this is where the ERI-project, the foundation initiative to popularize soil fertility management and conservation innovations was implemented. The purpose of the present study was to assess the impact of the ERI-project on farmers' investment in soil fertility management and conservation; rise in yields and revenues from sales in project farmer fields. Potato has traditionally been cultivated in Kabale district, and this district is renowned for producing $50 \%-60 \%$ the total volume of potato tubers in Uganda [10].

Kamuganguzi sub-County, in particular was purposively selected because it had farmers who were previously involved in the ERI-Project, as well as those who were not. Parishes involved in the ERI-project interventions included Buranga, Katenga and Kicumbi. Non-ERI-project potato farmer parishes included Kasheregyenyi, Kyasano and Mayengo.

\subsection{Identification of Participating Households}

Households that participated in the present study were identified from the ERIProject records and community meetings held in the initial stages of the study. Households that participated in the ERI-Project activities were found in Buranga, Katenga and Kicumbi parishes. ERI-Project registers and potato sales membership records that showed frequencies of sales and volumes of potato delivered and sold, were major sources of information for this purpose. Farmers from ERI-Project who consistently sold potato for over a period of five years to urban markets were identified and selected. Non-ERI-Project households, were also se- 
lected to act as the study controls. The latter farmers were sourced from the neighboring parishes of Kasheregyenyi, Kyasano and Mayengo, where the ERIProject never operated.

Therefore, households from non-ERI-Project that were considered to participate in the present study identified themselves and were supported by other potato farmers in the parish community meetings, based on consistence of at least five consecutive years of potato production and sale to non-urban market. Participating households were solely those that participated in potato production for either urban or non-urban markets for five consecutive years. Verification of selected households producing potato for sale was done through collection and sales records at the collection centers for urban market linked farmers. Farmers not linked to urban markets were ascertained by verifying the presence of potato fields.

\subsection{Household Interviews}

Interviews were administered to the ERI-Project and non-project farmer groups using a semi-structured questionnaire. Among the 120 households ERI-Project farmers (urban market linked), 76 of them had consistently supplied potato to the market for at least five consecutive years. The survey targeted household heads or members of the households stratified according to wealth category (WC) and gender, actively involved in potato production activities. The questionnaire was pre-tested and modified for fitness for the purpose, using non-target farmers producing potato for urban and non-urban markets within the same or nearby sub Counties. Hence, using a formula adopted from [11], 68 households were purposively selected for household interviews based on gender and four WCs identified (Equation (1)).

$$
n=\frac{N}{\left[1+N(e)^{2}\right]}
$$

where:

$$
\begin{aligned}
& n=\text { Sample size. } \\
& N=\text { Population size. } \\
& e=\text { Level of significance. }
\end{aligned}
$$

$$
n=\frac{76}{\left[1+76(0.05)^{2}\right]}=68
$$

From each WC, a maximum of five households where possible, were randomly selected for the interviews. Where a WC had less than five households, then all of them were considered for interviews. As such, 46 households that consistently produced potato for non-urban markets for at least five consecutive years were also stratified in four WC, and were all considered for interviews. Data on socio-economic and bio-physical parameters, as well as investments in soil fertility management and conservation innovations in potato-grown fields at household 
level were captured.

\subsection{Management and Analysis of Data from Household Interviews}

The survey data were subject to extensive cleaning for consistency, completeness and correctness. Consistency checking included systematic reviewing to avoid data duplications. The data collected were entered into a Microsoft Excel spreadsheet for further management. Also, in this case, collected data were categorized or collapsed depending on their consistencies, closeness and variation from the mean. The cleaned data were later analyzed using R-statistical package. The dependent variables included use of soil fertility management and conservation innovations (FYM, mineral fertilizers, agro-forestry, trenches, bush-fallows and grass-bunds). The independent variables were market types, WCs of households, nature of labor used on farm (family and hired labor), characteristics of the household head (gender, age, marital status, and education level), farm size and household size.

Continuous variables were retained in the format of the coded questionnaire. For non-continuous variables, responses were recorded as binary variables (i.e. 1 = Yes, 0 otherwise). The dependent variable, a binary response was farmers' decision to use or not to use a given soil fertility management and conservation innovation in the potato-grown fields. For testing multiple adoption decisions, the dependent variable was obtained by summing the dependent variables for the different technologies and ranking them to obtain an index of adoption. Thus a " 0 " for example, represented farmers with no adoption of soil fertility management and conservation innovation, "1" for those with one soil fertility management and conservation innovation, and so on, for potato-grown fields.

\subsection{Determinants of Farmers' Adoption of Multiple Innovations}

The study analyzed farmers' use of multiple soil fertility and conservation innovations so as to understand the intensity of use of these innovations and how they were influenced by 12 socioeconomic factors (Table 1). The Ordered Probit Model was used in the data analysis due to its capacity to handle a case of two outcomes of an ordinal dependent variable (a dependent variable for which the potential values have a natural ordering, as in poor, fair, good, excellent). Ordered outcomes were modeled sequentially as a latent variable $y^{*}$, where $y^{*}$ was an underlying unobservable measure of household's adoption of soil fertility management and conservation innovations in the potato-grown fields in number and it was specified as follows (Equation (2)).

$$
y_{i}^{*}=x_{i} \beta+u_{i}
$$

For a $f^{\text {th }}$ farm household where normalization is considered, the regressors $x$ do not include an intercept. When $y^{*}$ is $<1$, it indicates that adoption of soil fertility management and conservation innovations by farm household is low. On the other hand, when $y^{*}$ is $>1$, it indicates increase in number of soil fertility management and conservation innovations adopted by farm household. 
Table 1. Variables used in the ordered Probit model in a potato soil fertility study.

\begin{tabular}{|c|c|}
\hline Variable & Description \\
\hline Market type & $\begin{array}{l}\text { Type of farmer-market } \\
(0=\text { Non-urban market; } 1=\text { Urban market })\end{array}$ \\
\hline Gender & Sex of the household head ( $1=$ Male, $2=$ Female $)$ \\
\hline Age & Age in years of the household head (Years) \\
\hline Education & $\begin{array}{l}\text { Education level of the household head } \\
(0=\text { No formal education, } 1 \text { = Primary, } 2=\text { Post-primary })\end{array}$ \\
\hline Cattle & Possession of heads of cattle on the farm $(1=$ Yes, $0=$ No $)$ \\
\hline Small ruminants & Possession of small ruminants on the farm $(1=$ Yes, $0=\mathrm{No})$ \\
\hline Pigs & Possession of pigs on the farm $(1=$ Yes, $0=\mathrm{No})$ \\
\hline Household size & $\begin{array}{l}\text { Number of members eating and staying together } \\
\text { in the homesteads for long time }\end{array}$ \\
\hline Hired labor & Use of hired labor on the farm $(1=$ Yes, $0=$ No $)$ \\
\hline Family labor & Use of household labor on the farm $(1=$ Yes, $0=$ No $)$ \\
\hline Farm size & Aggregated land size owned by the household (ha) \\
\hline Household members & $\begin{array}{l}\text { Number of household members working } \\
\text { permanently on the farm }\end{array}$ \\
\hline
\end{tabular}

For $\mathrm{m}$ categories following a standard ordered probability model, the probability of observing outcome $i$ corresponds to the following (Equation (3)):

$$
\operatorname{Pr}\left(\text { outcome }_{j}=i\right)=\operatorname{Pr}\left(K_{i-1}<X_{i} \beta+\mu_{i} \leq \alpha_{i}\right)
$$

where:

$\mu_{i}$ is assumed to be normally distributed with a standard normal cumulative distribution function. The coefficients $\beta_{1}, \cdots, \beta_{k}$ is jointly estimated with the cut-points $\alpha_{1}, \alpha_{2}, \cdots, \alpha_{k-1}$ where $k$ is the number of possible outcomes.

The three categories of levels of adoption: moderate (outcome 1), high (outcome 2), and very high (outcome 3 ) formed the dependent variables as ordered 1,2 , and 3 , respectively. The dependent variable for any farmer with a sum of interventions was 1) one intervention was scored One; 2) two and three interventions was scored Two; and 3) more than three interventions was scored Three.

\section{Results}

Table 2 presents the results of the Ordered Probit Model for the factors that influence farmer's use of multiple soil fertility and conservation innovations. Both the coefficients and marginal effects estimated are presented. The likelihood ratio statistics were significant at one percent indicating that the coefficients of independent variables were not jointly equal to zero. The chi-square tests of the equality of the three cutoff points for each model were not rejected at one percent level of significance. The significant differences in the cutoff points indicated that the four categories differed and could all be included in the model. The results focused on marginal effects; with emphasis on famers practicing 
Table 2. Parameter estimates and marginal effects of ordered Probit Model analysis of socioeconomic factors influencing farmers' adoption of soil fertility management and conservation innovations in potato-grown fields.

\begin{tabular}{|c|c|c|c|c|c|c|c|c|c|}
\hline \multirow{2}{*}{ Variables } & \multirow{2}{*}{ Coef. } & \multirow{2}{*}{ Std. Err. } & \multicolumn{2}{|c|}{ Outcome (1) } & \multicolumn{2}{|c|}{ Outcome (2) } & \multicolumn{2}{|c|}{ Outcome (3) } & \multirow{2}{*}{$\mathbf{X}$} \\
\hline & & & $\mathrm{dy} / \mathrm{dx}$ & Std. Err. & $\mathrm{dy} / \mathrm{dx}$ & Std. Err. & $\mathrm{dy} / \mathrm{dx}$ & Std. Err. & \\
\hline Sex of the household head $(1=\mathrm{M} ; 0=\mathrm{F})$ & -0.263 & 0.292 & -0.053 & 0.061 & -0.045 & 0.048 & -0.055 & 0.065 & 0.67 \\
\hline Age of the household head (years) & $0.025^{\star * *}$ & 0.010 & $-0.005^{\star \star}$ & 0.002 & $0.005^{\star * *}$ & 0.002 & $0.005^{\star * *}$ & 0.002 & 48.18 \\
\hline Education & $0.956^{* * *}$ & 0.317 & $0.162^{\star *}$ & 0.059 & $0.182^{* * *}$ & 0.075 & $0.180^{* * *}$ & 0.064 & 0.43 \\
\hline Household size (Number) & -0.047 & 0.063 & 0.009 & 0.012 & -0.009 & 0.012 & -0.009 & 0.012 & 5.73 \\
\hline Total farm size (ha) & -0.014 & 0.033 & 0.003 & 0.007 & -0.003 & 0.006 & -0.003 & 0.007 & 2.62 \\
\hline $\begin{array}{l}\text { Household members working on the farm } \\
\text { (Number) }\end{array}$ & 0.018 & 0.072 & -0.003 & 0.014 & 0.003 & 0.014 & 0.004 & 0.014 & 2.71 \\
\hline Household labor (Number) & 0.341 & 0.460 & -0.059 & 0.068 & 0.076 & 0.118 & 0.058 & 0.067 & 0.88 \\
\hline Hired labor (Number) & $1.055^{\star * *}$ & 0.303 & $-0.183^{\star \star \star}$ & 0.062 & $0.183^{\star *}$ & 0.070 & $0.210^{\star * *}$ & 0.068 & 0.52 \\
\hline Cattle (Number) & -0.012 & 0.108 & 0.002 & 0.021 & -0.002 & 0.020 & -0.002 & 0.022 & 1.02 \\
\hline Chicken (Number) & $0.083^{*}$ & 0.045 & $-0.016^{\star}$ & 0.010 & $0.016^{*}$ & 0.009 & $0.016^{*}$ & 0.010 & 2.06 \\
\hline Small ruminants (Number) & $0.143^{* * *}$ & 0.059 & $-0.028^{\star *}$ & 0.014 & $0.027^{*}$ & 0.014 & $0.028^{* * *}$ & 0.012 & 2.66 \\
\hline Pigs (Number) & -0.124 & 0.150 & 0.024 & 0.030 & -0.023 & 0.029 & -0.025 & 0.031 & 0.22 \\
\hline Market linkages (Number) & $2.051^{\star * *}$ & 0.467 & $0.254^{* * *}$ & 0.065 & $0.279^{* * *}$ & 0.079 & $0.407^{\star * *}$ & 0.101 & 0.47 \\
\hline /cut1 & -0.408 & 0.822 & & & & & & & \\
\hline /cut2 & 0.562 & 0.830 & & & & & & & \\
\hline /cut3 & 1.980 & 0.836 & & & & & & & \\
\hline No. of obs & 97.000 & & & & & & & & \\
\hline LRchi2 (17) & 78.850 & & & & & & & & \\
\hline Prob > chi 2 & 0.000 & & & & & & & & \\
\hline Pseudo R2 & 0.295 & & & & & & & & \\
\hline Loglikelihood & -94.208 & & & & & & & & \\
\hline
\end{tabular}

Note: ${ }^{* *} \mathrm{P}<0.001,{ }^{* *}=\mathrm{P}<0.05$ and $^{\star}=\mathrm{P}<0.10$ significance level. The omitted category is for the no Intervention practiced.

more than three interventions while taking non-practicing $(\mathrm{y}=\mathrm{zero})$ as a base category.

The age of household head exhibited a positive and significant effect on intensity of practicing more than three interventions at $1 \%$ level of significance. This implied that older household heads were more likely to have higher adoption intensities than their younger counter parts. All other variables kept constant, relative to not practicing any intervention, age of household head significantly decreased the likelihood of implementing one intervention but increased the likelihood of implementing more than three interventions. The value marginal effect for age of households practicing more than three intervention is 0.005 ; in- 
dicating that the probability of full implementation of all the interventions is likely to increase by $0.5 \%$ for each additional year above the average age.

Similarly, number of small ruminants (goats and sheep) owned by a household positively and significantly affected practicing the interventions related to soil fertility management and conservation in the potato-grown fields at $5 \%$ level of significance. A very small increase in number of small ruminants owned by a household increased the change in probability of practicing more than three interventions by $2.8 \%$ holding other factors constant. This implies that the households with many small ruminants were able to take other interventions.

Education level (captured as dummy $1=$ completed pre-primary level), was positive and significant at $5 \%$. Implying that compared to uneducated farmers, increasing the educational level above the average, increased the likelihood of households practicing many interventions. Results show the value marginal effects for education level for households practicing more three interventions is 0.180 ; indicating that the education level is more likely to increase the likelihood of full implementation of all the interventions. This implies the educated farmers were better implementers of more than three interventions.

The coefficient on market access (captured as a dummy for $1=$ urban access), was positive and significant across all farmer categories. This suggests that compared to farmers under non-urban market access,, farmers with urban market access were more likely to implement many soil fertility interventions. For instance, all other variables kept constant, relative to none practicing famer category, urban market access significantly increases the likelihood of using one intervention by $6.5 \%, 7.9 \%$ for practicing two interventions and $10.1 \%$ for practicing more than three interventions.

Similarly, farmers' use of hired labor exhibited a positive and significant (at $1 \%$ level) relationship in using more than three interventions in soil fertility management and conservation innovations in the potato-grown fields. This indicated that households with more capacity to hire labor for potato production were more likely to have higher adoption intensities compared to their counterparts with limited capacity.

All other variables kept constant relative to not practicing any intervention of soil fertility management and conservation innovations in the potato-grown fields, use of hired labor significantly reduced the likelihood of households to use one intervention. The value marginal effect for use of hired labor of households having more than three interventions in soil fertility management and conservation is 0.21 ; indicating that the probability of full implementation of all the intervention was likely to increase by $21 \%$ for each additional labor above the average.

\section{Discussion}

Farmer's age played a significant role in influencing farmer's likelihood to invest or not to invest in soil fertility management and conservation innovations in potato-grown fields (Table 2). Elderly farmers were more likely to invest in more 
than three interventions related to the promoted soil fertility management and conservation innovations in the potato-grown fields compared to their counterparts who were younger in age. Elderly farmers used their vast experience and confidence gained over years in the potato production and productivity, which made them significantly invest in more than three interventions. This finding was also similarly reported elsewhere that there was positive relation between the age of the household head and the number of relevant soil fertility management and conservation innovations used on the farm [12]. Unlike the younger farmers, elderly farmers had more resources and access to them such as land that could be used as collateral to access credit used to purchase inputs such as fertilizers and also hire labor to implement soil fertility management and conservation innovations in the potato-grown fields. Younger farmers, more especially the youths, could hardly invest in soil fertility management and conservation innovations due to high costs associated with their use.

Elderly farmers had accumulated small ruminants over years and, therefore, had greater access to FYM that could be used as soil inputs in the potato-grown fields. Younger farmers often had none or few ruminants and, therefore, could not have enough manure for potato production. Further, younger farmers often had smaller pieces of land compared to elderly farmers and this was a disincentive for them to invest in soil conservation structures such as trenches and grass bunds that required space of not less than $0.5 \mathrm{~m}$ in width along the contours.

Limited adoption of soil fertility management and conservation by younger farmers, more especially the youths contradicted with what was reported elsewhere that younger farmers were more likely to adopt soil fertility management and conservation innovations due to being energetic and enthusiastic compared to elderly farmers [13]. This situation is possible where younger farmers have land and other resources that could enable them invest in soil fertility management and conservation innovations. Contrary to this, youths often did not own land and therefore, had limited access to it and yet only the household head made decisions on its use. Pieces of land owned by younger farmers were often characterized by being small ( $<0.5$ acres), shallow soils, far from homesteads, located on steep slopes, and poor in soil fertility. Under these conditions, younger farmer often moved outside their communities in search for off-farm jobs and therefore less available to implement soil fertility management and conservation innovations in the potato-grown fields [9].

Education level played a significant role in influencing farmer's likelihood to invest in soil fertility management and conservation innovations in the potato-grown fields. Household heads with higher education were more likely to invest in more than three interventions related to soil fertility management and conservation innovations in the potato-grown fields compared to their counterparts with low education levels. This finding is in agreement with what was reported elsewhere that farmers with higher education levels often adopted soil fertility management and conservation innovations [14]. This stems from far- 
mer's experience gained from schools, where they could have trained them in some aspects in related to agricultural production. Farmers with higher education were often quick to analyze issues and, therefore, used multiple soil fertility management and conservation innovations after scrutinizing their importance. Such farmers often interacted with extension workers where they obtained more advice on the different interventions. Farmers with higher education were able to read the literal materials that were often given to them during training workshops conducted within and outside the community. Exposure of farmers to knowledge could have had an influence on their likelihood to invest in multiple interventions reported [15].

Access to hired labor played a great role in likelihood of farmers to invest in higher intervention intensities related to multiple soil fertility management and conservation innovations. Some of the promoted soil fertility management and conservation innovations such as FYM, construction of trenches and bunds were more labor intensive. Soil conservation structures are known to be effective in trapping sediment and blocking run-off, but are labor-intensive and cost-intensive to build and involve additional long-term repair costs [16]. Hence, farmers with higher capacity of hiring labor were more likely to invest in more than three interventions related to soil fertility management and conservation in the potato-grown fields.

Farmers who could not afford to hire labor were less likely not to invest in any of the promoted soil fertility management and conservation innovations. Such farmers also possessed limited land, and therefore could not invest in soil conservation structures that required adequate space for construction so that they are effective in controlling soil erosion and surface runoff. Hired labor is often expensive in the highlands of south-western Uganda, more especially in the wet season when it is most needed. The youths, who could provide labor on farms are not interested in agricultural activities due to drudgery involved, and most of them often left rural areas to urban centers in search for off farm jobs [7].

Enhanced market access played a significant role in influencing farmer's likelihood to invest in interventions related with soil fertility management and conservation in potato-grown fields. Farmers selling potato to urban markets were more likely to invest in interventions under different intensities. Use of soil fertility management innovations involved extra costs that included buying the soil inputs, transport and application of the amendments into the soil. Further, use of soil conservation innovations involved construction and maintenance of soil conservation structures such as trenches and grass bunds. Farmers linked to urban markets were more likely to invest in such interventions at different levels of intensity. This finding is in agreement with what was reported elsewhere [17] that smallholder farmers in East Africa were able to invest in soil fertility management and conservation innovations when linked to profitable markets. Farmer's likelihood to invest in soil fertility management stemmed from the increased proceeds from the potato sales, bargaining power farmers obtained through collective action. Farmers often bought fertilizers in bulk whenever, they take their 
potato produce to urban markets.

\section{Conclusion}

Enhancing farmers' access to urban markets translated into increased likelihoods of farmers to invest in soil fertility management and conservation innovations at different levels of intensities. When farmer's knowledge is enhanced and the farmers are later linked to urban markets, their household income increases and they are more likely to invest in soil fertility management and conservation innovations.

\section{Recommendations}

Enhancing farmer's linkage to urban markets is more likely to positively influence farmers' decision to invest in soil fertility management and conservation innovations at different levels of intensities. Hence, there is need to scale out efforts made by CIAT in related to urban market enhancement to empower farmers' investments in soil fertility management and conservation innovations in potato-grown fields.

\section{Conflicts of Interest}

The authors declare no conflicts of interest.

\section{References}

[1] Xie, H., Huang, Y., Chen, Q., Zhang, Y. and Wu, Q. (2019) Prospects for Agricultural Sustainable Intensification: A Review of Research. Land, 8, Article No. 157. https://doi.org/10.3390/land8110157

[2] Tittonell, P., et al. (2010) The Diversity of Rural Livelihoods and Their Influence on Soil Fertility in Agricultural Systems of East Africa-A Typology of Smallholder Farms. Agricultural Systems, 103, 83-97. https://doi.org/10.1016/j.agsy.2009.10.001

[3] Theriault, V., Smale, M. and Haider, H. (2017) How Does Gender Affect Sustainable Intensification of Cereal Production in the West African Sahel? Evidence from Burkina Faso. World Development, 92, 177-191. https://doi.org/10.1016/j.worlddev.2016.12.003

[4] Kabale District Council, Kabale District Local Government, the Republic of Uganda (2016) Map of Kabale District by Population Density by Sub County.

[5] Feyisa, B.W. (2020) Determinants of Agricultural Technology Adoption in Ethiopia: A Meta-Analysis. Cogent Food \& Agriculture, 6, Article ID: 1855817. https://doi.org/10.1080/23311932.2020.1855817

[6] Thornton, P.K., Kristjanson, P., Förch, W., Barahona, C., Cramer, L. and Pradhan, S. (2018) Is Agricultural Adaptation to Global Change in Lower-Income Countries on Track to Meet the Future Food Production Challenge? Global Environmental Change, 52, 37-48. https://doi.org/10.1016/j.gloenvcha.2018.06.003

[7] Milder, J.C., Majanen, T. and Scherr, S.J. (2011) Performance and Potential of Conservation Agriculture for Climate Change Adaptation and Mitigation in Sub-Saharan Africa. Ecoagriculture Discussion Paper No. 6.

[8] McIntire, J.M. (2014) Transforming African Agriculture. Global Journal of Emerging Market Economies, 6, 145-179. https://doi.org/10.1177/0974910114525697 
[9] Bedeke, S., Vanhove, W., Gezahegn, M., Natarajan, K. and Van Damme, P. (2019) Adoption of Climate Change Adaptation Strategies by Maize-Dependent Smallholders in Ethiopia. NJAS: Wageningen Journal of Life Sciences, 88, 96-104. https://doi.org/10.1016/j.njas.2018.09.001

[10] Mejia-Mantilla, C. (2020) Impact of Fiscal Policy on Poverty and Inequality in Uganda: Fiscal Incidence Analysis Using the Unhs 2016/17. World Bank Policy Research Working Paper No. 9051. The World Bank, Washington DC, NW, 41 p.

[11] Bàrberi, P. (2013) Agricultural Sustainability. Elsevier, Singapore.

[12] Muzira, R., Vanlauwe, B., Basamba, T., Rwakaikara, S.M. and Wanjiku, C. (2015) Challenges and Opportunities for Agricultural Intensification of the Humid Highland Systems of Sub-Saharan Africa. Springer, Cham. https://doi.org/10.1007/978-3-319-07662-1

[13] Priegnitz, U., Lommen, W.J.M., van der Vlugt, R.A.A. and Struik, P.C. (2020) Potato Yield and Yield Components as Affected by Positive Selection during Several Generations of Seed Multiplication in South-Western Uganda. Potato Research, 63, 507-543. https://doi.org/10.1007/s11540-020-09455-Z

[14] Diwekar, U. and David, A. (2015) Uncertainty Analysis and Sampling Techniques. In: BONUS Algorithm for Large Scale Stochastic Nonlinear Programming Problems, Springer, New York, 9-25. https://doi.org/10.1007/978-1-4939-2282-6 2

[15] Kassie, M., Jaleta, M., Shiferaw, B., Mmbando, F. and Mekuria, M. (2013) Adoption of Interrelated Sustainable Agricultural Practices in Smallholder Systems: Evidence from Rural Tanzania. Technological Forecasting and Social Change, 80, 525-540. https://doi.org/10.1016/j.techfore.2012.08.007

[16] Ade, A.T. and Bosede, S.J. (2016) Ordered Probit Analysis of Factors Influencing Farmers' Contributions to Climate Change Adaptation Decisions in Southwest Nigeria. Trends in Agricultural Economics, 10, 1-11. https://doi.org/10.3923/tae.2017.1.11

[17] Oseko, E. and Dienya, T. (2015) Fertilizer Consumption and Fertilizer Use by Crop (FUBC) in Kenya: Technical Report AfricaFertilizer.org (AFO) (2015), p. 47. 